\title{
Cementitious Composites Reinforced With Polypropylene, Nylon and Polyacrylonitile Fibres
}

\author{
H.R. Pakravan ${ }^{1, a}$, M. Jamshidi ${ }^{2, b}$, M. Latifi ${ }^{3, ~ c}$, F.Pacheco-Torgal ${ }^{4, d}$ \\ ${ }^{1}$ Department of Textile Engineering, Textile Research \& Excellence Center, Amirkabir University of \\ Technology, Tehran Polytechnic, Iran \\ ${ }^{23}$ Department of Polymer,Building and Housing Research Center, Amirkabir University of \\ Technology, Tehran Polytechnic,Iran \\ ${ }^{4}$ Research Unit C-TAC, Sustainable Construction Group, University of Minho, \\ Guimarães, Portugal \\ ahamid.pakravan@gmail.com, bjamshidi@bhrc.ac.ir, ${ }^{d}$ torgal@civil.uminho.pt
}

Keywords: Pull-out test, adhesion strength, polymeric fibres, microstructure

\begin{abstract}
This paper compares the adhesion strength between three polymeric fibres (polypropylene (PP), nylon66 (N66) and polyacrylonitrile (PAN)) embedded in a cement paste. The specimens were prepared at a water to cement ratio (w/c) of 0.5 , and tested after 7,14 and 28 curing days. It was found that although the adhesion between the polymeric fibres to the cement matrix is an important factor, the energy absorption capacity or energy dissipation ability of the fibres plays a more important role in the improvement of the cementitious composites fracture toughness. Scanning electron micrographs was used to characterize the fibres surface before and after the Pullout tests.
\end{abstract}

\section{Introduction}

Cementitious composites have a high compressive strength but low tensile strength. The use of fibres is needed to overcome that disadvantage leading to a material with good compressive and tensile strengths but also with a long post-crack deformation (strain softening) [1].

At first, asbestos fibers were used in industrial processes to produce fiber reinforced cement sheets [2,3]. However, due to cancer health risks [4,5] the Directive 83/477/EEC and amending Directives 91/382/EEC, 98/24/EC; 2003/18/EC and 2007/30/EC forbid the production of cementitious products based on fiber silicates (asbestos). Mineral fibers are now being replaced by synthetic fibers like polyvinyl alcohol (PVA) and polypropylene to produce fiber-cement products using the Hatscheck process [6].

The performance of cementitious composites depends on the type of fibres, their properties, fibre surface and cross section and the properties of the matrix, and fibre/matrix interface [7].

Also the adhesion strength between the fibres and the cement matrix is a crucial aspect governing the performance of cementitious composites. The adhesion strength is usually evaluated by the Pull-out tests [8].

The relationship between the Pull-out load and the displacement of the fibre, when it is pulled out from the cement matrix serves as an important parameter in the design of cement composite materials. The fibre/matrix adhesion is ruled by mechanical anchorage and by friction, depending on the chemical and mechanical properties of both phases [9].

Many investigations have been conducted on the evaluation of adhesion between fibres and the cement matrix [10-12]. The importance of the interaction between the fibres and the cement matrix has been found to be a critical parameter in the composite performance, which led to interface modification techniques to achieve the desired properties [13-16].

Fibre to cement matrix adhesion allows stress transfer between them. Thereafter, fibre Pull-out behavior is contributed to energy absorption ability of fibers in cementitious composites. Regarding the importance of this behavior in composite materials, fibre/cement interface has been studied [1720]. 
The improvement of cement composite toughness is a critical factor, which corresponds to the changes in the propagation of micro-cracks into major fractures by energy absorption during the bridging actions of reinforcing fibres at crack tip [21].

The aim of the present work is to characterize the adhesion characteristics of three polymeric fibers (polypropylene, nylon66 and polyacrylonitile) to the cement matrix.

\section{Experimental}

Materials. The cement used in this study was ordinary Portland type II. Three types of polymeric fibres (polypropylene, nylon66 and polyacrylonitrile) were used. Physical properties of the fibres are shown in Table 1.

Table 1. Properties of the polymeric fibres

\begin{tabular}{|c|c|c|c|c|}
\hline $\begin{array}{c}\text { Fibre } \\
\text { type }\end{array}$ & $\begin{array}{c}\text { Tensile strength } \\
{[\mathrm{MPa}]}\end{array}$ & $\begin{array}{c}\text { Diameter } \\
{[\mu \mathrm{m}]}\end{array}$ & $\begin{array}{c}\text { Density } \\
{\left[\mathrm{gram} / \mathrm{cm}^{3}\right]}\end{array}$ & $\begin{array}{c}\text { Elongation at } \\
\text { break }(\%]\end{array}$ \\
\hline PP & 330 & 25 & 0.91 & 180 \\
\hline N66 & 1120 & 26 & 1.14 & 32 \\
\hline PAN & 310 & 40 & 1.19 & 48 \\
\hline
\end{tabular}

The specimens were prepared using a cement paste with a water to cement ratio $(\mathrm{w} / \mathrm{c})$ of 0.5 . The embedded length of all fibers was $10 \mathrm{~mm}$. After demoulding, specimens were subjected to a humidity chamber at temperature of $23 \pm 2{ }^{\circ} \mathrm{C}$ and $100-5 \%$ of relative humidity. The Pull-out tests were carried out on the specimens after 7,14 and 28 curing days.

Pull-out Test. The pull-out tests were carried out by an INSTRON testing machine (Tinius Olsen) at the crosshead rate of $0.02 \mathrm{~mm} / \mathrm{s}$. The free length of the single fiber was $10 \mathrm{~mm}$.

Microstructure Study. The Pulled-out fibers from the cement matrix were also characterized using the SEM analysis.

\section{Results and Discussion}

Pull-out Results. N66 Fibres. The pull-out behavior of N66 fibres from the cement paste at 7, 14 and 28 days of curing is illustrated by stress-displacement curves in Fig. 2.

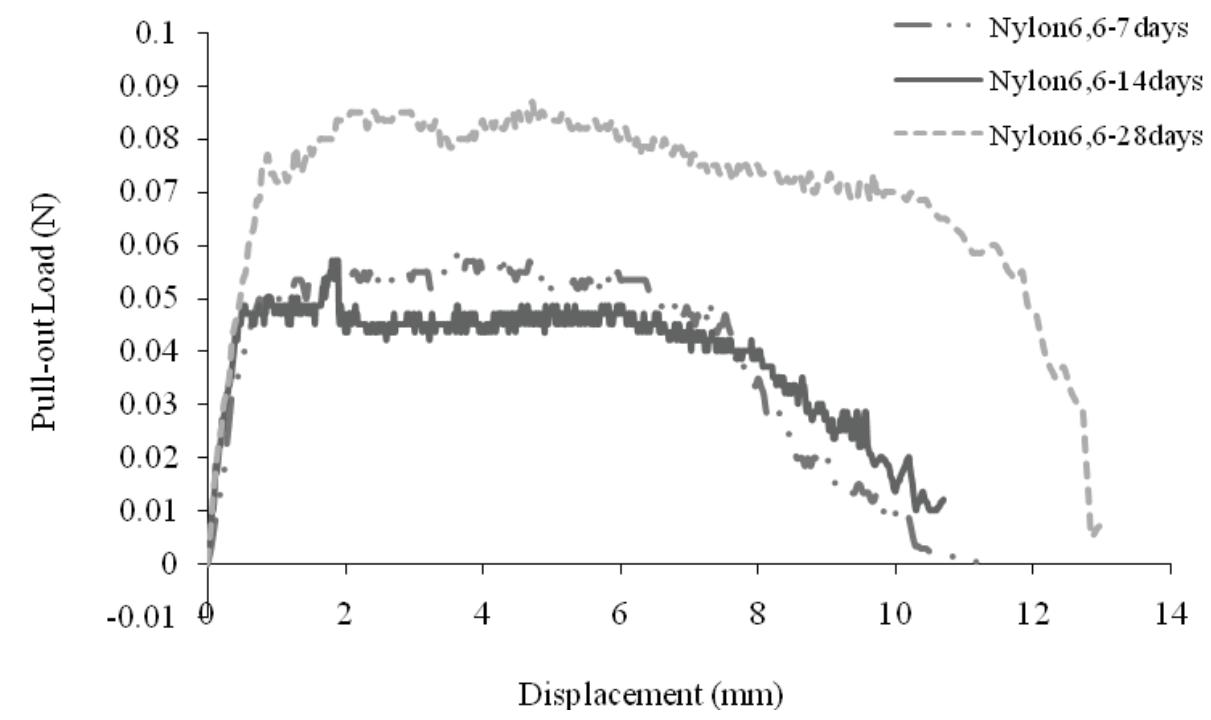

Figure 2. Pullout curve of nylon66 specimens for different curing periods 
PP Fibres. The Pull-out behaviors of the PP fibres from the cement matrix at 7, 14 and 28 days of curing, are shown in Fig. 3.

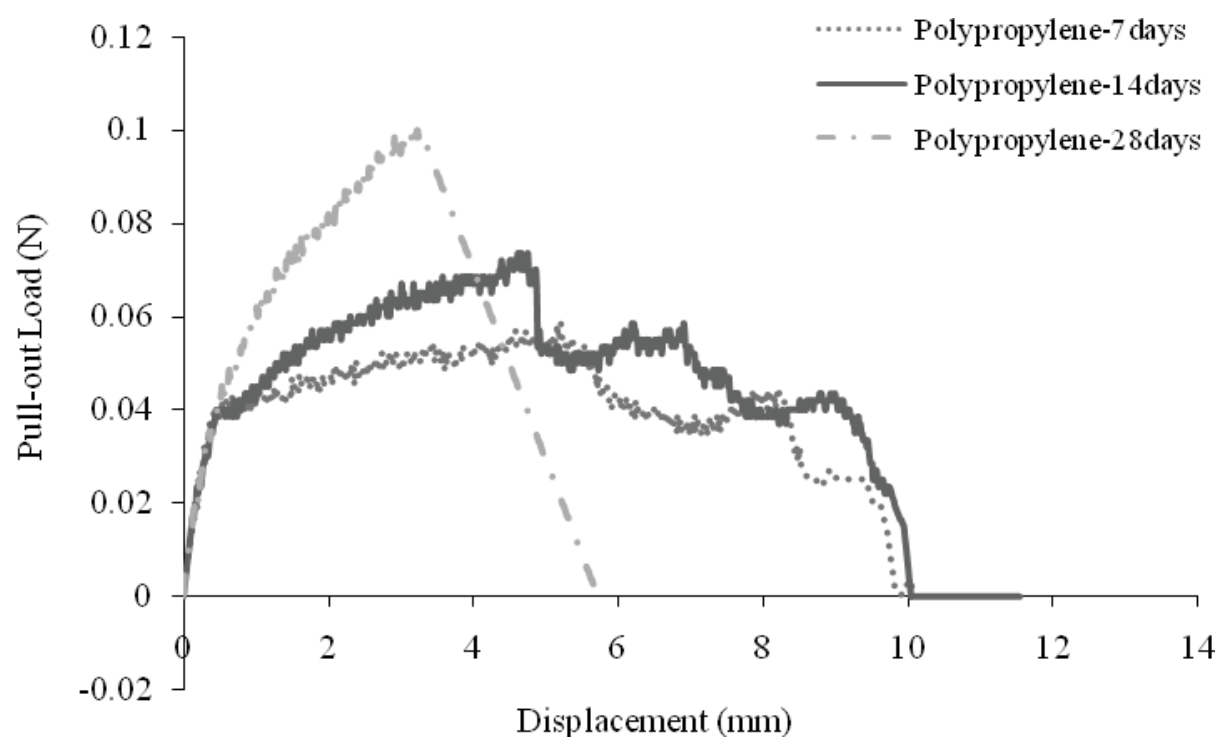

Figure 3. Pullout curve of polypropylene specimens for different curing periods.

The slip-stick behavior of pull-out curves for 7 and 14 days of the cured specimens indicates the mechanical interactions between fibres and surrounding matrix. The results represent that there was no significant difference between the Pull-out of 7 and 14 days cured specimens. The figure shows that PP fibre have been pulled-out without failure in 7 and 14 days cured specimens, but in 28 days, fibre rupture occurred before complete Pull-out took place. In case of 28 days cured specimens, the Pull-out force increases to a certain value and then suddenly drops down to zero. This can be due to the adhesion strength between PP fiber and cement matrix that is increased until it gets close to the fibre strength and after that the fibre is fractured during Pull-out.

PAN Fibres. Fig. 4 represents the Pull-out behavior of PAN fibres from the cement paste after 7, 14 and 28 days of curing. The Pull-out specimens of 7 and 14 cured days were pulled-out completely through cement matrix. Similar to the PP and PAN fibres were the rupture occurred during the pullout. Which is due to low tensile strength and also good adhesion of the PAN fibers to the cement paste.

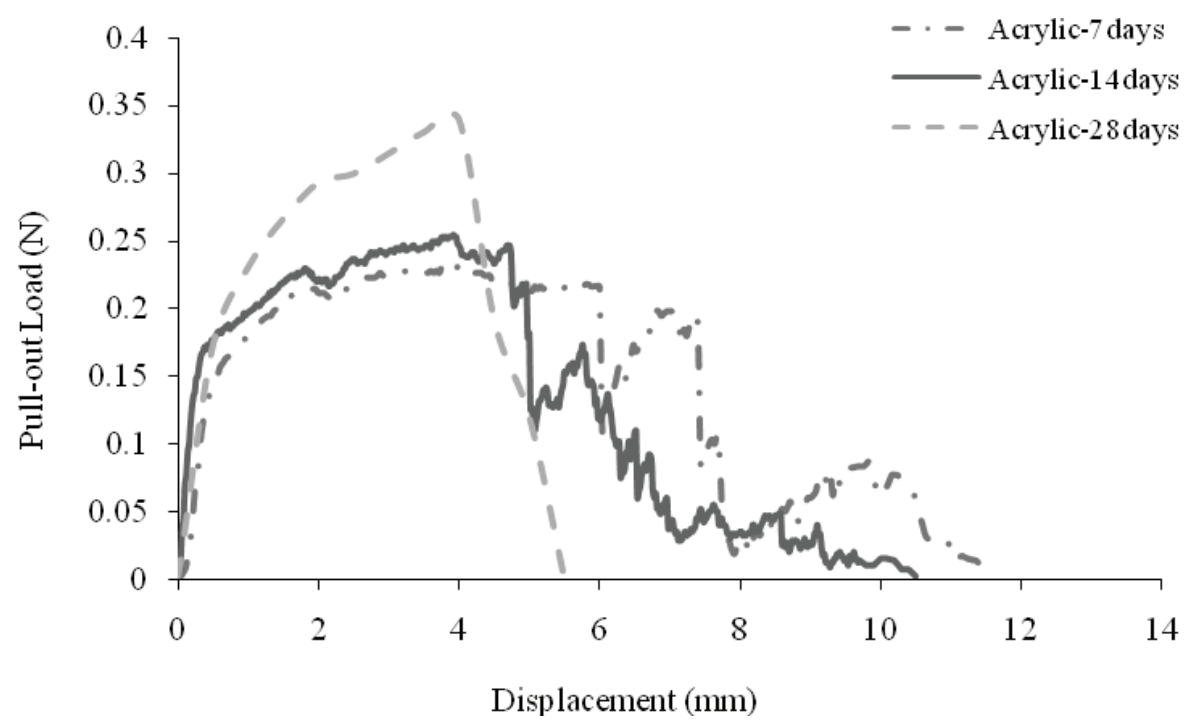

Fig. 4. Pullout curve of polyacrylonitrile specimens for different curing periods 
By consideration the pull-out curves in Fig. 5, it is evident that only N66 fibres were entirely pulled-out from the cement matrix without any breakage and other fibers are ruptured during pullout. It can be seen that PAN fibers show much higher pull-out strength in comparison to PP and N66 fibers.

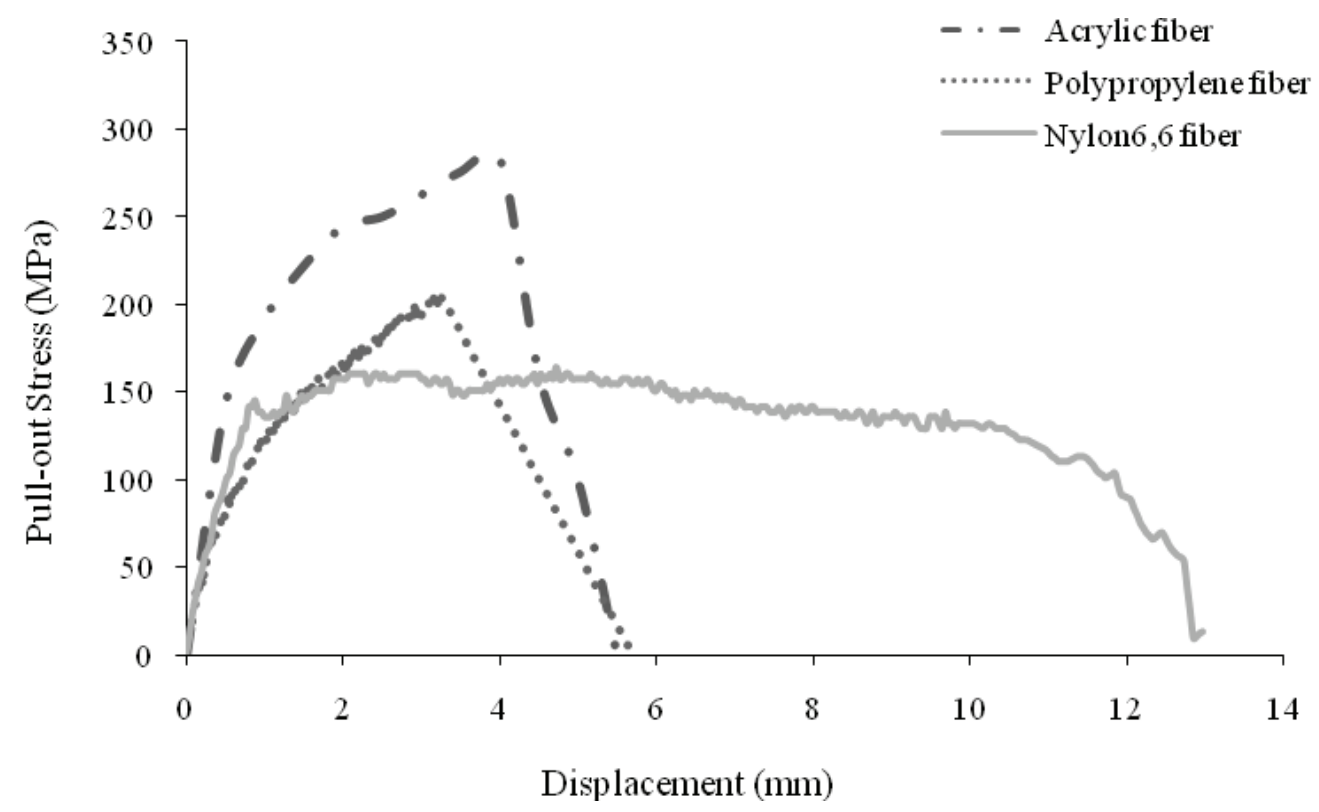

Fig. 5. Pull-out behavior of different fibres at 28 days curing.

It is rater obvious that N66 fibres, despite of excellent pull-out behavior, showed the weakest interfacial adhesion properties. Since the area under pull-out curves is considered the energy absorption capacity of fibres. It follows that N66 fibres show more energy absorption behavior than the other fibres. Other authors [22] show that fibres which have a high adhesion to a cementitious matrix (e.g. PVA fiber) ruptured during pulling-out. Then the tensile strain capacity of cementitious matrix reinforced by this type of fibre was limited.

\section{Microstructure Analysis}

Scanning Electron Microscopy (SEM). The surfaces of the pulled-out fibres were examined using SEM. Also, fibre surface were observed before the pull-out test for comparison. The observed valley along the longitudinal direction of the PAN fibre is related to the bean shape of its cross section (Fig. 5.a). Figure 5.b shows the adhered cement hydrates on the pulled-out PAN fibre surface.
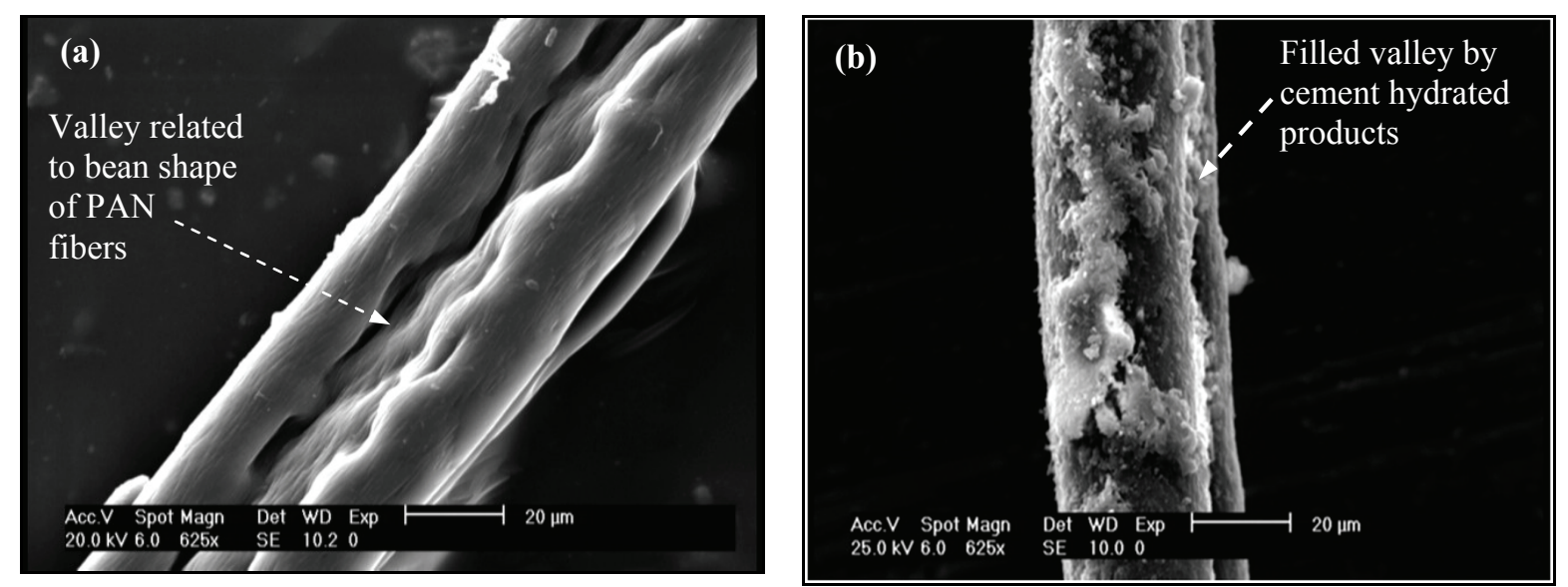

Figure 5. SEM micrographs of PAN fibre,

(a) Before embedment, (b) after pulled-out from the cement matrix. 
This reveals the chemical adhesion between the cement matrix and PAN fibers. Due to the affinity of hydrophilic PAN fibres to the cement matrix, chemical interactions will be expected. Because of the excellent adhesion between these materials, cement hydration products nucleated and grown on the surface of PAN fibre. Surface images of PP fibre before and after pull-out test are shown in Fig. 20. The textures observed on fibre surface (Fig. 6.a) are related to the fibre spinning process. By considering fibres images after the pull-out tests, mechanical damages were observed (Fig. 6.b).
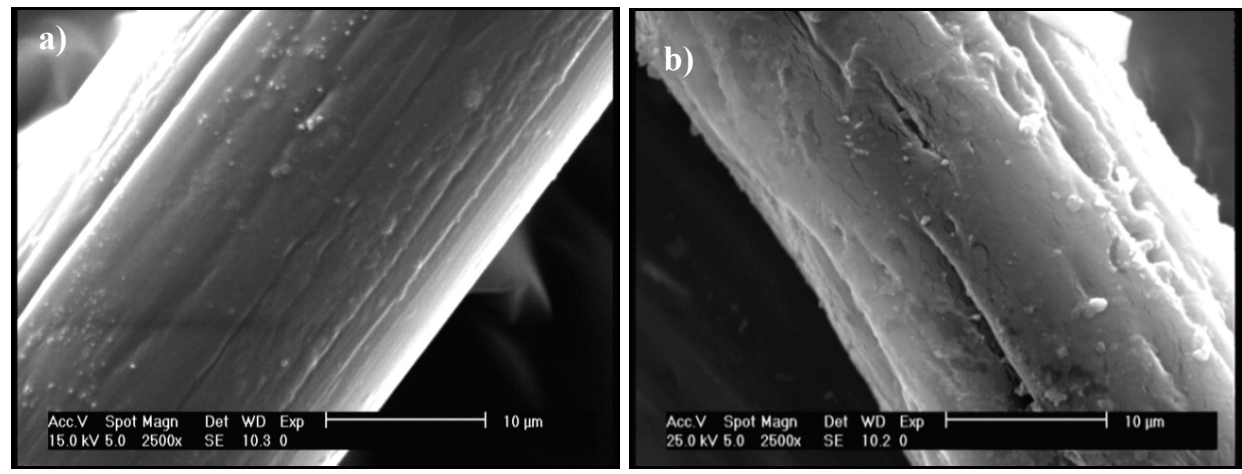

Figure 6. SEM micrographs of PP fibre,

(a) Before embedment, (b) after pulled-out from the cement matrix.

The image confirms the lack of chemical adhesion between the fibre and the cement matrix. The deep scratched areas on the fibre surface are attributed to the mechanical interlocking of large crystals of $\mathrm{CH}$ and PP fibre surface. These crystals resist against the pull-out of PP fibres and cause the plastic deformations on the fibre surface. Due to the hydrophobic nature of PP fibres, water bleeding occurs around the fibres.

The N66 fibers were characterized using SEM analysis (Fig. 7). Fig. 7.b clearly indicates the cement particles adhered to the fibre surface.
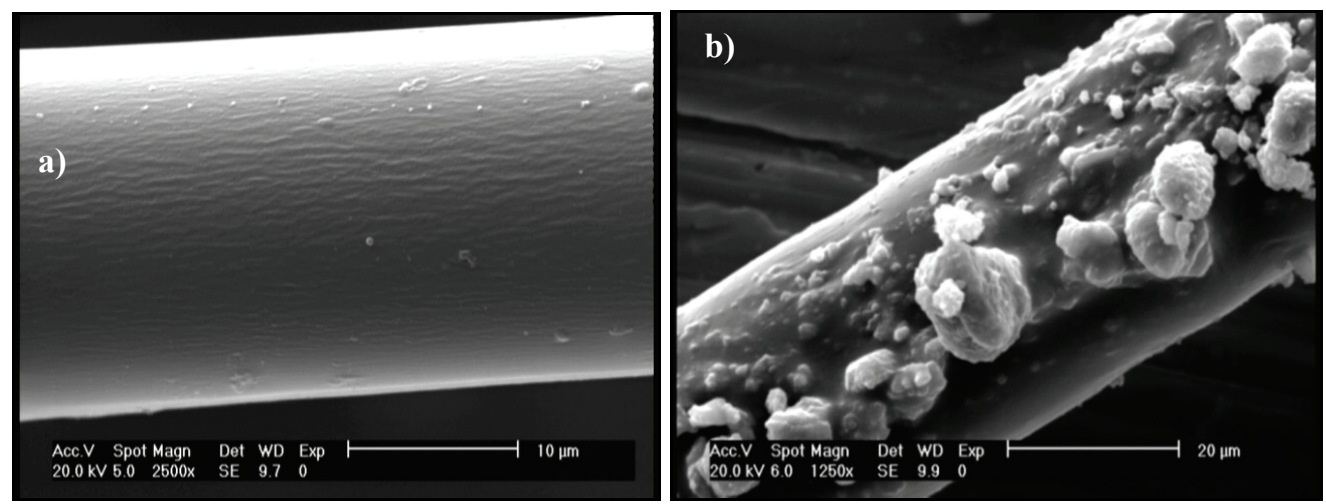

Figure 7. SEM micrographs of N66 fibre,

(a) Before embedment, (b) After pulled-out from the cement matrix.

The shape of the adhered crystals confirms that cement hydration products are nucleated and grown on the N66 fibre surface. Microscopic analysis also demonstrates that the surface of N66 fibres has not been deformed like PP fibres which is due to their higher tenacity.

\section{Conclusions}

The present investigation showed that pull-out behavior of all tested fibres were almost the same for 7 and 14 days cured specimens. Furthermore, it was found an increase in pull-out load for all tested fibres for 28 days cured specimens. Results showed that only N66 fibres can undergo pull-out load and draw out completely from matrix without rupture due to its high tenacity. Although PAN and PP fibres showed higher adhesion strength than N66 fibres, they ruptured at the maximum sustained load due to weak tensile strength with respect to their adhesion to the cement matrix. In spite of the 
lack of chemical adhesion between PP fibres and cement matrix, it showed better adhesion due to the mechanical interlocking and friction to the matrix. Results also show that N66 fibre in spite of a weaker adhesion to cement matrix in comparison to PP and PAN fibres showed higher energy absorption capacity and toughness during the pulling-out test.

\section{References}

[1] A. Bentur, S. Mindess, Fiber Reinforced Cementitious Composites. US: Elsevier Science Publishing Ltd, (1990).

[2] A. Pye, A Review of Asbestos substitute materials in industrial applications. J Hazard Mater 3 (1979)125-147.

[3] E.Willden, A guide to the art of asbestos cement, London: J. E. Williden Publishers (1986).

[4] K. Azuma, I. Uchiyama, Y. Chiba, J.Okumura, Mesothelioma risk and environmental exposure to asbestos: Past and future trends in Japan, International Journal of Occupational and Environmental Health 15 (2009) 166-172.

[5] S. Kumagai, N.Kurumatani, Asbestos fiber concentration in the area surrounding a former asbestos cement plant and excess mesothelioma deaths in residents, American Journal of Industrial Medicine 52 (2009) 790-798.

[6] S.Ikai, J. Reicher, A. Rodrigues, V. Zampieri, Asbestos-free technology with new high toughness polypropylene (PP) fibers in air-cured Hatschek process, Construction and Building Materials 24 (2010)171-180.

[7] D.Kim, A.Naaman, E. El-Tawil, Comparative flexural behavior of four fibers reinforced cementitious composites, Cem Concer Compos 30 (2008) 917-928.

[8] C. Leung, N. Ybanez, Pull-out of inclined flexible fiber in cementitious composite, ASCE J Eng Mech 123 (1997) 239-246.

[9] M. Andrzej, Cement-Based Composites Second Edition. New York: Taylor \& Francis (2009).

[10] A.Peled, E. Zaguri, G. Marom, Bonding characteristics of multifilament polymer yarns and cement matrices, Composites Part A 39 (2008) 930-939.

[11] S. Singh, A. Shukla, R.Brown, Pullout behavior of polypropylene fibers from cementitious matrix, Cem Concr Res 34 (2004) 1919-1925.

[12] A. Bentur, Role of interfaces in controlling durability of fiber-reinforced cements, J Mater Civ Eng 12 (2000) 2-7.

[13] A.Bentur, A.Peled, D.Yankelevsky, Enhanced bonding of low modulus polymer fiberscement matrix by means of crimped geometry, Cem. Concr Res 27, (1997)1099-1111.

[14] V.Li, C.Wu, S.Wang, A.Ogawa, T.Saito, Interface tailoring for strain-hardening PVA-ECC, ACI Mater Journal 99 (2002) 463-472.

[15] H.Wu, V.Li, Fiber/cement interface tailoring with plasma treatment, Cem Concer Compos 21 (1999) 205-212.

[16] B. Felekoglu, K. Tosun, B.Baradan, A comparative study on the flexural performance of plasma treated polypropylene fiber reinforced cementitious composites. J Mater Process Technol 209 (2009) 5133-5144.

[17] V.Li, Y.Chan, H.Wu, Interface strengthening mechanisms in polymeric fiber reinforced cementitious composites, In: Proc. Int. Symp., Brittle Matrix Composites. Warsaw: IKE and Woodhead Publ, 1994. pp. 7 - 16.

[18] T. Kanda, V.Li, Effect of fiber strength and fiber-matrix interface on crack bridging in cement composites, J Eng Mech 3 (1999) 290-299.

[19] B. Mobasher, C.Li, Effect of interfacial properties on the crack propagation in cementitious composites. Adv Cem Based Mater 4 (1996) 93-105.

[20] Y. Chan, V.Li, Age effect on the characteristics of fiber/cement interfacial properties. J Mater Sci 32 (1997)5287-5292.

[21] B. Cotterell, Y. Mai, Fracture mechanics of cementitious materials. Chapman and Hall (1996).

[22] T. Kanda, V. Li, Interface property and apparent strength of a high strength hydrophilic fiber in cement matrix. ASCE J Mater Civ Eng 10 (1998) 5-13. 